\title{
Dynamic and collaborative business networks in the fashion industry
}

\author{
Ahm Shamsuzzoha ${ }^{\mathrm{a}}$, Timo Kankaanpaa ${ }^{\mathrm{a}}$, Luis Maia Carneiro ${ }^{\mathrm{b}}$, Ricardo Almeida $^{\mathrm{b}}$, Andrea Chiodi $^{\mathrm{c}}$, Rosanna \\ Fornasiero $^{\mathrm{d}}$
}

\author{
${ }^{a}$ University of Vaasa, Finland, ${ }^{b}$ INESC Porto, Portugal, ${ }^{c}$ Synesis Consortium, Italy, ${ }^{d}$ CNR-ITIA, Italy
}

\begin{abstract}
In order to stay competitive and avoid being smashed by large companies, SMEs need to establish and manage dynamic and non-hierarchical networks to respond to market opportunities, ensuring a quick response, unique products with competitive prices and high product quality. This paper proposes an innovative methodological approach and ICT platform to support non-hierarchical collaboration between SMEs for customised product design and manufacturing. The ICT services are based on mapping a methodology on an open source platform in order to apply low cost solutions to SMEs. Two case studies in the fashion industry have been analysed and used to test the proposed approach for network management.
\end{abstract}

Keywords: non-hierarchical collaboration, fashion industry, virtual organisation, case study.

\section{Introduction}

The dynamic business environment and today's fierce competition has encouraged manufacturing companies, especially small and medium sized enterprises (SMEs), to build collaborative business networks (CBN) in order to reach specific business goals. The $\mathrm{CBN}$ can be defined as a group of heterogeneous companies running for a determined period of time (temporary or permanent) to create value within the companies. A CBN can have a similar form to a virtual organisation (VOs), for example, or virtual enterprises (VEs), extended enterprises, business communities (BC) and virtual organisation breeding environments (VBE) (Afsarmanesh and Camarinha-Matos 2005, Camarinha-Matos et al. 2008, Romero and Molina 2009, Romero et al. 2010). A CBN is usually formed when a business opportunity is identified and the partner organisations combine their resources and their most suitable skills and capabilities to seize the opportunity (Camarinha-Matos et al. 2008, Chituc et al. 2009). It is dissolved once the predefined business opportunity has been met and the network performance has been evaluated and stored for future use. This CBN promotes success in business by promoting enhanced collaboration, new business models and up-to-date technological capabilities, which are fundamental to improving the decision-making process (Camarinha-Matos and Afsarmanesh 2007).

The concept of collaborative business has developed, following a long evolution process over the last few years. It emerged during the 1990s with names such as virtual company, virtual enterprise (VE), or virtual corporation (VO) (Davidow and Malone 1992, Nagel and Dove 1995). Other popularised collaboration terms, such as Business-to-Customer (B2C) and Business-to-Business (B2B) are also used due to generalised access to the Internet and the fast development of World Wide Web technology. Appel and Behr (1998) introduced one of the first references to a (partial) theoretical foundation for VOs as the application of the transaction-cost theory, while Ahuja and Carley (1998) described VOs as structural aspects of the collaborative network. Tolle et al (2002) and Zwegers et al (2003) have attempted to organise and categorise reference models for VOs. The concept of Collaborative Networked Organisations (CNOs) was introduced by Camarinha-Matos and Afsarmanesh (2004). Collaboration among a number of enterprises and working together through VOs was presented by Camarinha-Matos and Afsarmanesh (2005) and Afsarmanesh and Camarinha-Matos (2008).

In networked business, various collaborative reference frameworks are identified during the maturity period of enterprise collaboration. The Zachman Framework for Enterprise Architectures (Zachman 1987) establishes a common enterprise-wide information system and provides a set of perspectives to describe and design complex enterprise network systems. CIM-OSA (Vernadat and Kosanke 1992), GRAI-GIM (Doumeingts et al. 1993), GERAM (IFIP-IFAC 2003) frameworks are developed based on underlying cultural perspectives of enterprise modelling. The Virtual Enterprise Reference Architecture and Methodology (VERAM), as proposed by Zwegers et al (2003), facilitates the modelling process by providing guidelines and characteristics to build the VEs and networks. ICT-driven development and common practices on VE/VO implementation frameworks was initiated by Camarinha-Matos et al (2005) through the PRODNET project (Katzy et al. 2005). ARCON (A Reference model for Collaborative Networks), a collaborative framework is defined by Afsarmanesh and Camarinha-Matos $(2005,2008)$ for modelling different forms of collaborations, namely VBE (Virtual Breeding Environment), VO, Professional Virtual Community and Virtual Team. Romero et al (2008) proposed VBE instantiation methodology to achieve required functionalities and meet collaborative goals. Another collaborative framework, the Virtual Organization Breeding Methodology (VOBM), was developed as part of the ECOLEAD project to define the structure of VBE and VO architectures in a service-oriented architecture (Paszkiewicz and Picard 2009),

Recent developments in ICT can help manufacturing companies form and operate within a CBN. Business collaboration requires appropriate tools and platforms, architectures and frameworks to support interoperability 
in heterogeneous and globally distributed companies (Myers 2006, Chituc et al. 2009). The use of ICT can influence the nature of collaborative activities by supporting the real-time monitoring and management of the collaboration processes (Chituc and Azevedo 2006).

The aim of this research is to facilitate the process of creating, joining and managing collaborative networks for SMEs by using (i) methodological aspects in the formation and operation of CBNs, and (ii) implementing an ICT-based platform to monitor and manage the real-time CBN's operational activities. The functionality of the proposed methodology and ICT platform for building the CBN is presented with two real implementation cases. Both cases focus on the fashion industries namely, the first on the Textile and apparel and second on the footwear industry. The outcomes from the implementation cases are presented in order to measure the performances of the presented methodology and ICT platform.

This study is part of the larger European research project, Net-Challenge, (Ref.: FP7-CP-FP229278-2) which aims to support SMEs in the creation and management of NHN for complex and customised product design and manufacturing. To this end, an integrated Framework was designed and developed, including a Methodology defining the conceptual background, general guidelines and best practices, reference collaboration processes and an ICT platform supporting the lifecycle of business communities and virtual organisations. For complex product design and manufacturing, two specific business scenarios are proposed namely, Engineer-to-Order (ETO) and Customise-to-Order (CTO).

The rest of the paper is organised as follows: Section 2 outlines the research methodology for the presented work, while Section 3 defines the Net-Challenge framework for non-hierarchical networks developed by the research team that includes the Net-Challenge methodology and the ICT platform. Section 4 presents the empirical study that was conducted within the two business cases to apply the theoretical research to real case studies. This section also introduces the backgrounds of both of the case companies (namely, apparel and footwear) along with the objectives and collaboration needs, the implementation of the methodology and the web platform and the evaluation of the new methodology. The overall outcome and lessons learnt from this study are discussed and conclusions are drawn with future research directions presented in Section 5.

\section{Research methodology}

In this research, a case study approach was adopted with the view to understand the formation of nonhierarchical collaboration among SMEs. In this paper, two case networks from the fashion industry namely, the textile, apparel and footwear industries are presented. Two companies from each industrial sector were identified and selected based on their product range, market share and position in the value chain, allowing them to play a key role in these networks. These companies were closely analysed, including their relationship with their main business partners, providing a clear view on the overall network. Some of their business partners were also interviewed.

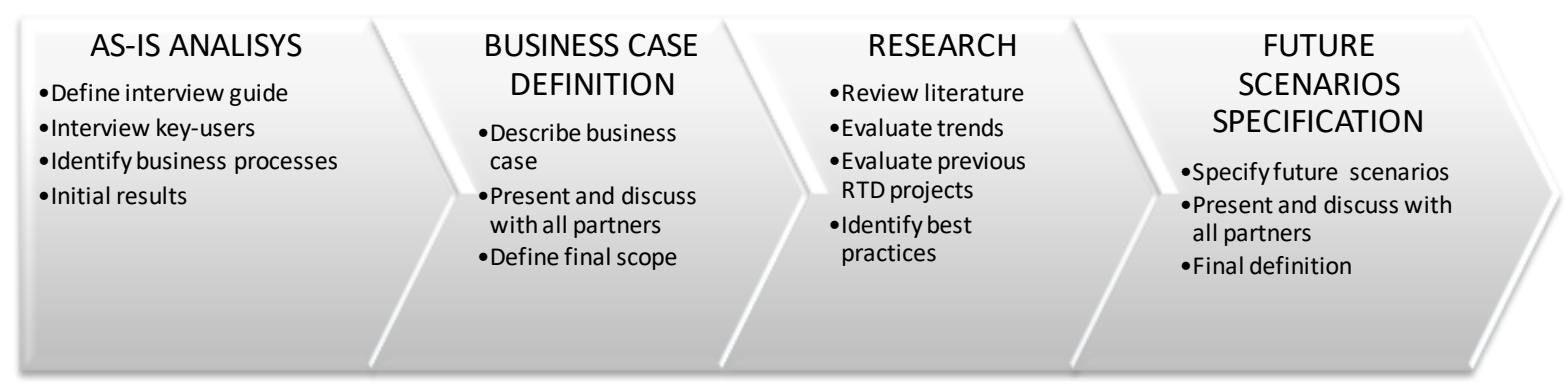

Figure 1. Research methodology.

Figure 1 presents the four phases of the research methodology defined for this study. The first phase focuses on analysing the initial situation, conducting interviews with key-users from business case companies. The study was conducted using structured interviews with management personnel from the pilot companies in order to collect, analyse and compare information, such as: business objectives, current products, target market, the resources available, manufacturing strategies, order fulfilment and sourcing strategies, distribution, potential partners and their selection criteria, networking practices and specific business constraints, the technologies implemented and constraints. In terms of networking practices, the key partners and networks, the established relationships, objectives, activities, and resources were all analysed.

An interview guide was developed to support the information acquisition process which covered the topics identified. The second phase focuses on defining the business case, including the scope of each case and the initial requirements identified. These results were presented and discussed during a brainstorming workshop (with all research partners and business case companies present). The result of this meeting and follow-up was a 
full description of the business cases which acted as a starting-point for detailed benchmark research (represented in the third phase) on current scenarios and best practices that are being applied in other companies and previous research projects. This third phase resulted in an initial study of possible business scenarios (which could fulfil business companies' needs).

The main objective of this phase was to analyse the relevant conceptual frameworks and current trends through detailed research of the literature, in order to discuss the best approaches with the business case companies and define the first future scenarios (that would be evaluated in short-stories presentation). In the final phase, a new set of working meeting and brainstorming sessions was organised with the business case company managers to identify relevant future business scenarios, where higher levels of collaboration were foreseen to respond to the business objectives identified. The future scenarios identified were presented and discussed with all of the partners involved in the process allowing them to make contributions, enhancing the conclusions and the relationship between the two business cases.

The aim of defining future business scenarios was to identify new activities that can create higher value for potential customers and offer increased competitiveness for SMEs. In non-hierarchical networks, this means offering high value products and services through direct partner involvement both up- and downstream in the value chain, including customers, suppliers and distributors. A trade-off between many different dimensions such as flexibility, time, cost and quality across the entire value chain has to be taken into consideration when defining the implementation of these networks. In non-hierarchical networks it may be easier to deal with these trades-offs because of the collaborative and shared view on processes, thus the maximisation of the overall performance of the Business Community is based on the flexibility of their response to the market and is ensured by the companies' complementary approach.

\section{The Net-Challenge Framework for non-hierarchical networks}

\subsection{The Net-Challenge Methodology}

The goal of the Net-Challenge Framework is to provide support for European SMEs in the creation and management of non-hierarchical collaborative networks for complex product design and manufacturing. The Net-Challenge Framework includes a Methodology, providing the conceptual background, implementation guidelines and reference processes, and an ICT platform to support the processes foreseen in the Methodology (Carneiro et al. 2010).

Non-hierarchical collaborative networks enable SMEs to share potential resources, knowledge and risks that allow them to seize larger value-adding business opportunities than they could when working alone. In order to obtain long-term business collaboration, the Net-Challenge Methodology proposes the creation of groups of companies that share common business interests, which are known as a Business Community (BC). A BC is a restricted group of companies, mainly SMEs, where trust can be built and communication streamlined to improve competitiveness in the market (Kankaanpää et al. 2010). The BC can be considered a particular VBE case (Afsarmanesh and Camarinha-Matos 2005), where some concepts are simplified and social networking software (Face book, Twitter, LinkedIn) is promoted. A BC generally orchestrates within the same region, in the same company or companies that form synergies and have the same cultural perspectives, such as in industrial clusters and industrial districts. Different forms of collaboration environments within the collaborative network are presented in Figure 2.

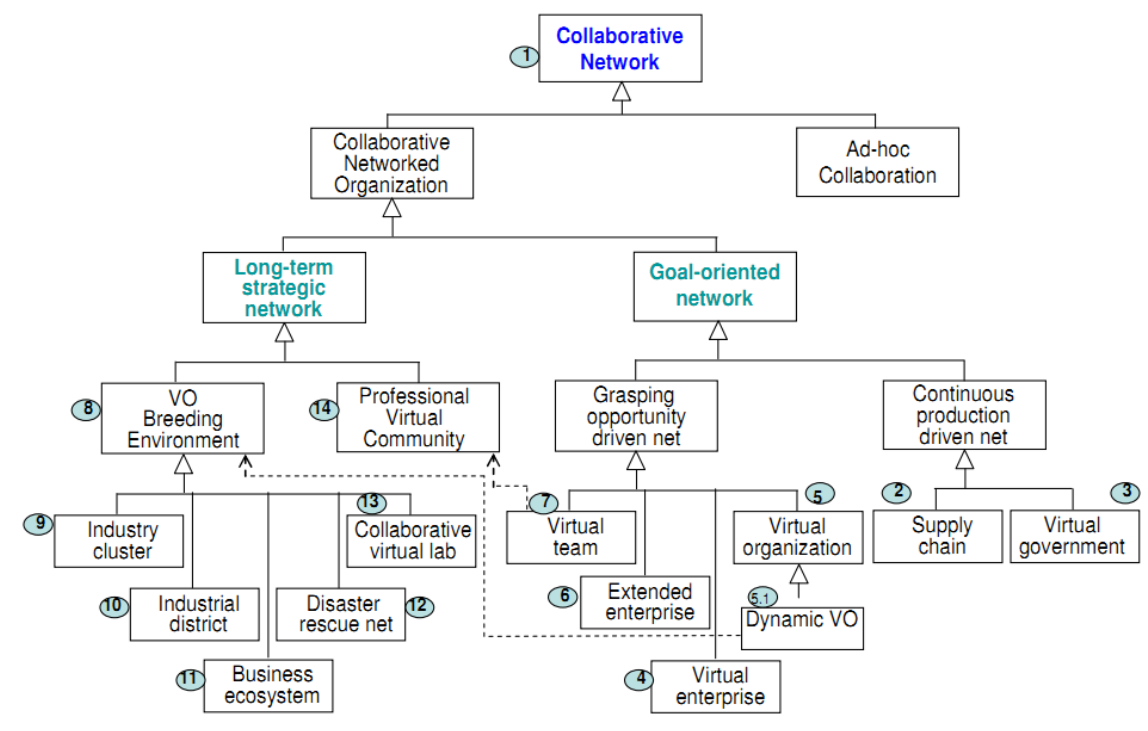


Figure 2. Various forms of collaboration within a collaborative network (from ECOLEAD_D52.3).

In these specific groups of companies, BCs, the Net-Challenge methodology aims to facilitate the creation of Virtual Organizations (VOs) and in particular, VOs for two typical scenarios regarding personalised and wide variety production, which are ETO (Engineer-to-Order) and CTO (Customise-to-Order) respectively. The high level VO lifecycle management for ETO and CTO scenarios within the dynamic business community is presented in Figure 3. The Net-Challenge Methodology high level structure for ETO and CTO VO management is composed of four main phases, namely; (i) Building, (ii) Forming, (iii) Operating and (iv) Dissolving (Shamsuzzoha et al. 2011).

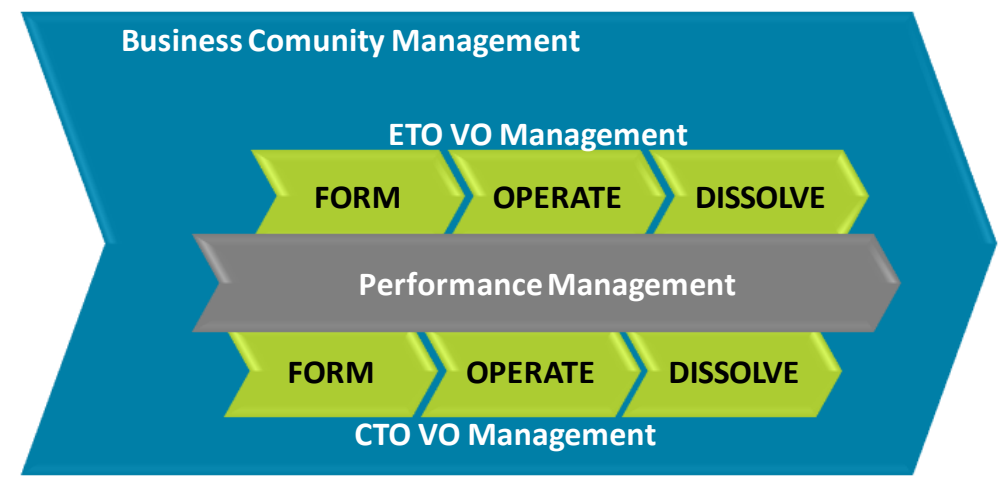

Figure 3. Generic life-cycle of ETO and CTO VO management.

In the Build phase, BCs are created according to potential partners' common business interests that are qualified based on standardised qualification criteria. During this phase, partners frequently interact in order to build trust with each other and share information and knowledge on creating a suitable environment for NHN. In NHN, partners collaborate with each other in a horizontal power sharing structure, where they enjoy equal power-sharing and control over each other. In the Build phase, the governance model has to be defined with the aim of creating a common set of cooperation agreements, common business rules and conditions, a common infrastructure and artefacts.

Once companies have agreed to create a BC they can create VOs according to the business opportunities arising in the market. The methodology supports them in three phases: Forming, Operating and Dissolving, which include different steps according to the scenario considered, the ETO and the CTO production. In the ETO production scenario, the objective is to develop a one-of-a-kind product according to specific customer needs, while in a CTO scenario, the objective is to develop a customised product based on a product platform. The ETO scenario is a customer-driven approach, while the CTO scenario is a market-driven approach.

In the ETO VO Form, a VO is formed to respond to a specific business opportunity and the output is to prepare a quotation. The high level steps needed to form an ETO VO are: collecting customer requirements, establishing contracts and NDAs (non-disclosure agreement), designing high level product concepts and collaborative planning. However, in the CTO VO Form, the aim of forming a VO is to develop a product platform, from where a stream of product variants can be easily developed. The high level steps in this phase are: analysing the market needs, establishing contractual and NDA agreements, defining a product platform and creating a business plan.

The objective of the ETO Operate phase is to manufacture a one-of-a-kind product, with a concept and quotation that was already developed in the Form phase. The high level steps in this phase are: ordering deployment, engineering the product, defining a detailed plan, executing production processes and managing risks, and managing abnormal situations during production process, known as 'events'. In the CTO Operate phase, the goal is to collaboratively develop a product platform and deliver variations of products from it. The high level steps in this phase are: defining a platform-based product family, identifying the product architecture, making variations of the product and specifying special requirements (white spots).

The final phase of the BC lifecycle is to Dissolve the VO. In the ETO VO Dissolve phase, the objective is to dissolve the $\mathrm{VO}$ once it has completed the mission to deliver a one-of-a-kind product to the client. In this phase, the most important activities, such as performance evaluation, organisation and archiving knowledge are all recorded and stored for use. In the CTO VO Dissolve phase, a VO is dissolved when the demand for the defined product platform is reduced to a level where the business collaboration is no longer profitable. The dissolution process for both the ETO and CTO production scenarios includes common tasks, such as assigning liabilities, share out, maintaining proprietary rights, evaluation reports from partners, collecting feedbacks from clients and VO performance feedback. The overall performance of the VO is maintained throughout the BC's lifecycle. 


\subsection{Net-Challenge ICT platform}

To support the efficient implementation of the Methodology and collaboration processes by SMEs, an ICT infrastructure and Decision Support Tools were designed and implemented. This ICT platform supports SMEs in the efficient formation and management of BCS and collaboration projects (VOs). Figure 4 presents the NetChallenge platform's simplified functional architecture.

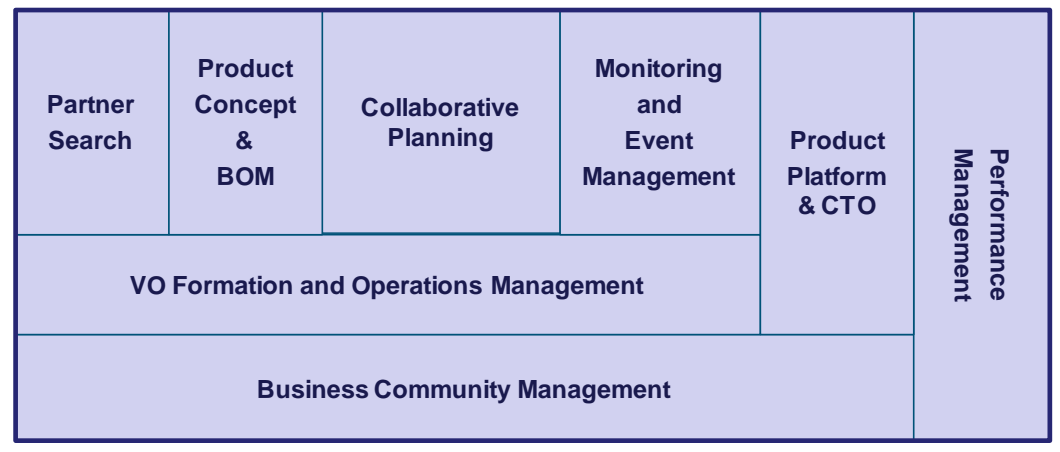

Figure 4. ICT platform functional architecture.

To support the BC management, a technical infrastructure permits, for example, easy and reliable information exchange and sharing between the participating companies, organising events, sharing news and wikis.

To support the creation and management of collaboration projects in VOs in an ETO scenario, several components are available to support the search for partners, the collaborative definition of product concepts and the respective Bill of Materials and Operations, collaborative planning, monitoring and event management.

The collaborative planning component helps core partners in a given VO negotiate and synchronise information planning in a heterarchic negotiation-based approach (Almeida et al. 2011). The monitoring and event management component is implemented as a light-weight flexible solution for executing risk and event management in VOs (Cunha et al. 2011). As part of the Net-Challenge system, this component offers capabilities for monitoring the execution of the planned activities and managing the negative effects of deviations in planned activities or if critical problems occur. The innovative content that results is the emphasised collaborative aspect that manages the negative impact of events.

To support the CTO scenario, a standard product configurator is integrated into the platform. This configurator makes it possible to define several family-based product platforms and each customer order is managed using the some functionalities as those in the ETO scenarios.

Finally, a component is foreseen to support the performance management in Business Communities and collaboration projects (VOs). It integrates goal setting and performance evaluation, considering both the individual and the network levels. The final goal is continuous performance improvement at BC and VO levels.

This platform was developed using two main technological components: Liferay (www.liferay.com) and Vaadin (www.vaadin.com). The first component is used to implement basic functionalities for the Business Community management. The specific and innovative features from the Net-Challenge platform were developed using Vaadin, in an integrated way with Liferay (portlets in Java's terminology).

\section{Empirical study: business cases}

The companies analysed produce complex and/or customised products for the fashion sector, with low volumes and high product varieties in their production processes. There are different definitions of product complexity and some dimensions that must be considered are (Hobday 1998): the quantity of sub-systems and components, the degree of customisation of components, the quantity of alternative component design paths, uncertainty/change in user requirements, the intensity of supplier involvement, the multilevel of BOM, the lifecycle of the product, the number of variants that will be manage concurrently.

In apparel and footwear companies the complexity of the product is given by the amount of variants (in terms of models, size, colour) that must be managed concurrently in each seasonal collection. In fact, in apparel and footwear sectors every season (4 to 6 months), each company can produce/manage an average of 300-400 different product models (variants) and each of them need to be designed, industrialised and produced in a collaborative way that involves, for example, component producers, raw material suppliers, stylists and retailers. In recent years, seasonal changes have become quicker and each customer now asks for a specific product with both personalised aesthetic and functional features. 
The descriptions of the case companies are summarised in Table 1 in terms of their country, business field, position in the supply chain, number of employees and annual turnover.

Table 1. Core companies directly involved in the project.

\begin{tabular}{|c|c|c|c|c|c|}
\hline Company & Country & Business field & $\begin{array}{c}\text { Position in the } \\
\text { supply chain }\end{array}$ & $\begin{array}{c}\text { Number of } \\
\text { employees }\end{array}$ & Turnover \\
\hline $\begin{array}{c}\text { Company } \\
\text { A }\end{array}$ & Portugal & Textile and apparel & $\begin{array}{c}\text { Design, project } \\
\text { management, } \\
\text { Marketing and } \\
\text { distribution }\end{array}$ & 23 & $5 \mathrm{M} €$ \\
\hline $\begin{array}{c}\text { Company } \\
\text { B }\end{array}$ & Portugal & Textile and apparel & $\begin{array}{c}\text { Supplier of } \\
\text { fabrics and design }\end{array}$ & 800 & $50 \mathrm{M} €$ \\
\hline $\begin{array}{c}\text { Company } \\
\text { C }\end{array}$ & Italy & $\begin{array}{c}\text { Footwear: assembly } \\
\text { company producing } \\
\text { customised shoes }\end{array}$ & $\begin{array}{c}\text { Assembler/produc } \\
\text { er }\end{array}$ & 10 & $0.5 \mathrm{M} €$ \\
\hline $\begin{array}{c}\text { Company } \\
\text { D }\end{array}$ & Italy & $\begin{array}{c}\text { Fabric producer for } \\
\text { Clothing and } \\
\text { Footwear }\end{array}$ & $\begin{array}{c}\text { Component } \\
\text { Supplier }\end{array}$ & 35 & $8.5 \mathrm{M} €$ \\
\hline
\end{tabular}

The two companies involved for each of the Business Cases - represent the core companies for the overall networks that will be analysed which involve an increased number of different partners and suppliers. The dimensions of the networks of the two business cases are presented in Table 2.

Table 2. The dimension of the networks of the business cases.

\begin{tabular}{|l|l|l|l|l|}
\hline $\begin{array}{l}\text { Business case } \\
\text { (BC) }\end{array}$ & $\begin{array}{l}\text { Product } \\
\text { lifecycle }\end{array}$ & $\begin{array}{l}\text { Number of new } \\
\text { models per year }\end{array}$ & $\begin{array}{l}\text { Total number of } \\
\text { partners for the } \\
\text { business case }\end{array}$ & $\begin{array}{l}\text { Number of } \\
\text { partners per } \\
\text { component }\end{array}$ \\
\hline $\begin{array}{l}\text { BC1: Textile and } \\
\text { Clothing } \\
\text { (companies A } \\
\text { and B) }\end{array}$ & $\begin{array}{l}3-4 \\
\text { months }\end{array}$ & $\begin{array}{l}\text { 3-400 models } \\
\text { (including size } \\
\text { variants) }\end{array}$ & $\begin{array}{l}\text { 10-15 (outsourcing of } \\
\text { production of clothes) } \\
40: \text { components } \\
\text { suppliers }\end{array}$ & $\begin{array}{l}\text { 2-4 for each } \\
\text { component }\end{array}$ \\
\hline $\begin{array}{l}\text { BC2: Footwear } \\
\text { (companies C } \\
\text { and D) }\end{array}$ & $\begin{array}{l}3-4 \\
\text { months }\end{array}$ & $\begin{array}{l}4-500 \text { models } \\
\text { (including size } \\
\text { variants) }\end{array}$ & $\begin{array}{l}10-15 \text { suppliers, 100 } \\
\text { outsourcers }\end{array}$ & Roughly 10 \\
\hline
\end{tabular}

The companies have been approached in order to identify their business requirements and the paths to new business scenarios have been defined according to the research methodology described above. When comparing the results of the analysis with the most important collaborative models in the literature, it became clear that these networks lack the proper tools or methodologies to select, establish and communicate with potential partners in their BCs in order to create strategic partnerships with their suppliers. For complex and customised product manufacturing the integration between design and partner selection is especially important. Building trust between potential partners seems to be the highest concern for this collaboration. There are also fears relating to confidentiality of information flow among partners and the type of collaboration they are looking for.

In such business environments, it appears easy for SMEs to build up NHNs, where companies could support each other (between core partners) in a horizontal relationship rather than in terms of vertical dependency. In such non-hierarchical relationships, case companies could share their resources, valuable information and valueadded activities. This trust building (mainly introduced during the Build Phase in the methodology) encourages them to introduce potential innovation in their product development processes and capture new market shares for business expansion. From this study, it became apparent that although the case companies were collaborating with other business networks, they were lacking IT-based tools and methodologies to track the real-time information, which could ensure the safety and confidentially of valued information that needs to be exchanged.

When a specific $\mathrm{VO}$ is required within a $\mathrm{BC}$, the most common way of communicating with partners is by phone, fax or email. Phone discussions are used for non-formal tacit knowledge exchange, especially during the creation of the network. Written emails are more formal to finalise the discussions initiated on the phone. None of these methods share the agreed decisions internally (inside the companies) or with other partners in the same VO. These types of communication also produce unstructured data results. Therefore, this research has defined a standard procedure for knowledge sharing for the case companies involved in collaborative networks.

\subsection{Collaborative Business Case 1}


Companies A and B are key members of this Case business network. Company A is a small company with a wide service approach (offering services that range from product design to the final delivery), while company B is internationally recognised for the production of high quality fabrics.

\subsubsection{Company backgrounds}

Company A's main goal is to offer ladies high quality clothing, combining the high quality of fabrics with an attractive design. This company participates in a broad value chain that covers all stages, from the design, modelling and production of samples, to custom production and delivery. The main product lines are ladies dresses and suits. Company A targets clothing designers and distribution chains in the medium to high market segments in countries such as Italy (major brands including Armani, Paola Frani and Max Mara), Germany, France (ETAM, Cop Copine, Caroll), the USA and niche markets.

Company A initially worked for "private label" customers (customers with their "own" collections) in a virtual manufacturing business model. The objective was to offer a complete service, including the engineering, sourcing, manufacturing and transportation of the apparel that was part of the client's collection. In 2008, Company A launched its own brand. This brand includes ladies clothing with modern, attractive and elegant styles, but with clear classical inspiration. This brand was initially marketed in northern Europe. The collections are characterised by their easy adaptability to several types of customers. With this brand, Company A is targeting the high/medium market segments, especially in countries such as Germany, the Netherlands, Switzerland, Ireland and Belgium. For the moment, Company A is selling in multi-brand stores, through commercial agents.

Company A is competing in very demanding markets with a low tolerance for failure. Therefore, product quality and design quality together with superior service and a competitive price are the major strengths. With regard to service, the most important aspect is the short lead time, but other aspects, such as the information supplied, are also considered. Company A wishes to perform better in the main competitive factor - lead time. Being located in Europe enhances their commitment to respecting a maximum delivery time of 5 weeks which has become a key competitive advantage over emergent suppliers from China and India.

However, Company A cannot compete strongly on price, mostly because its Portuguese suppliers have higher prices than other suppliers located in eastern countries. To reduce the risk factor, Company A promotes a network of design, weaving, confection and finishing companies, assuring high quality, fast response times and competitive prices.

Company B specialises in the production of textile fabrics for clothing, and has become one of the larger and better known manufacturers of fabrics in Europe. Company B also exports to most markets in the world. Company $\mathrm{B}$ is recognised for its competency in fabric design and finishing processes and for the high quality of its products, the most important of which are fabrics made from synthetic fibre.

Company B developed a supplier network from a vertically integrated company introducing increased flexibility and reduced risk. The objective has been to accommodate market changes and enlarge the product range. This company aims at higher levels in the value chain. For example it aims to develop more complete collections and promote the integration of client design teams with its own internal design teams and also develop client-specific products.

The objective is to reduce risk and reduce the inventory cost. These changes have created a new major challenge - reducing lead-time production series to less than 5 weeks. This has been considered a critical success factor in the European market as a result of the strong competition from countries like China and India.

\subsubsection{Objectives and collaboration needs}

In addition to the different business strategies adopted, both companies aim at excellent customer service and fast delivery (in order to guarantee their market position over their most direct competitors). Both companies aim to increase their flexibility in response to market changes, in terms of delivery times, cost reduction and product range enlargement. Considering today's global markets, these objectives are unachievable if working alone. Therefore, companies are encouraged to work in partnership with several companies (developing virtual organisations) to respond better to customer needs. This new business trend has revealed new challenges in terms of collaboration and cooperation strategies between partners.

To successfully work with this business trend, choosing the right partner is a critical step. A large effort is needed for these companies to select the best partners in different geographical locations. Close collaboration exists with design partners in Italian brand companies and multinational raw material suppliers, for example. The companies are involved in a broad value chain, that cover all stages from the design, modelling and production of samples, to custom production and delivery.

However, the initial involvement of these companies with partners followed traditional supply chain concepts. Company A proposes a delivery date to their customers based on a lead time of 5 to 6 weeks, based on 
a negotiation with potential suppliers in order to fulfil the delivery date and to keep the cost within the estimated value. Delivery reliability depends on the delivery reliability of the fabric suppliers and the delivery reliability of the manufacturers was initially below the company's expectations. For this reason, the due date for the suppliers is negotiated with a large safety margin. All of the communication performed with partners is based on unstructured data (e-mails, fax, phone calls) and no business process integration is available. This makes the negotiation process more inefficient. Another issue which concerns these companies is the lack of confidence in the delivery time promised by partners which means managers cannot make a sustainable decision.

\subsubsection{Implementation of the methodology and the ICT platform}

The research developed identified the need for collaborative environments to handle several critical business processes, such as Product Design and Production Planning, which demand a high level of communication between all the partners involved (initially mainly conducted in a manual and unstructured way, using e-mails and phone calls).

To support easy information communication and sharing, and informal collaboration with key partners, a closed business community supported by the ICT platform developed was implemented. The members of this Business Community were carefully selected by Company A and Company B. It is expected that this BC will slowly grow in terms of the number of members as they increase the trust level between them. The Business Community component of the Net-Challenge platform is also the entry point for the creation and management of VOs.

Collaborative planning is one of the most complex and time-consuming business processes in these scenarios, since several iterations are needed as well as up to date information on the local available capacity for each partner, to provide an accurate result. The proposed collaborative planning was planned to manage the negotiation process between core partners, aiming at a common plan to ensure the shortest possible delivery time and the fair distribution of costs and benefits. Each partner can access a shared planning tool and when accepting or proposing a new change, instead of distributing this information manually to the other partners, it automatically becomes visible for all partners in a graphical user interface. Figure 5 presents a sample screen of the web-based application proposed, which makes it possible to share operations planning with all partners. This example presents the initial operations allocated to each partner, as well as the foreseen initial and end dates for each operation. These are also presented in a Gantt chart (on the right side of the panel). Each time a new activity is added or changed, it becomes visible to all partners involved and a new overall delivery time is calculated and evaluated (according to partner's local theoretical capacity). This allows partners to simulate different allocations and perform a what-if analysis before confirming any change to other partners.

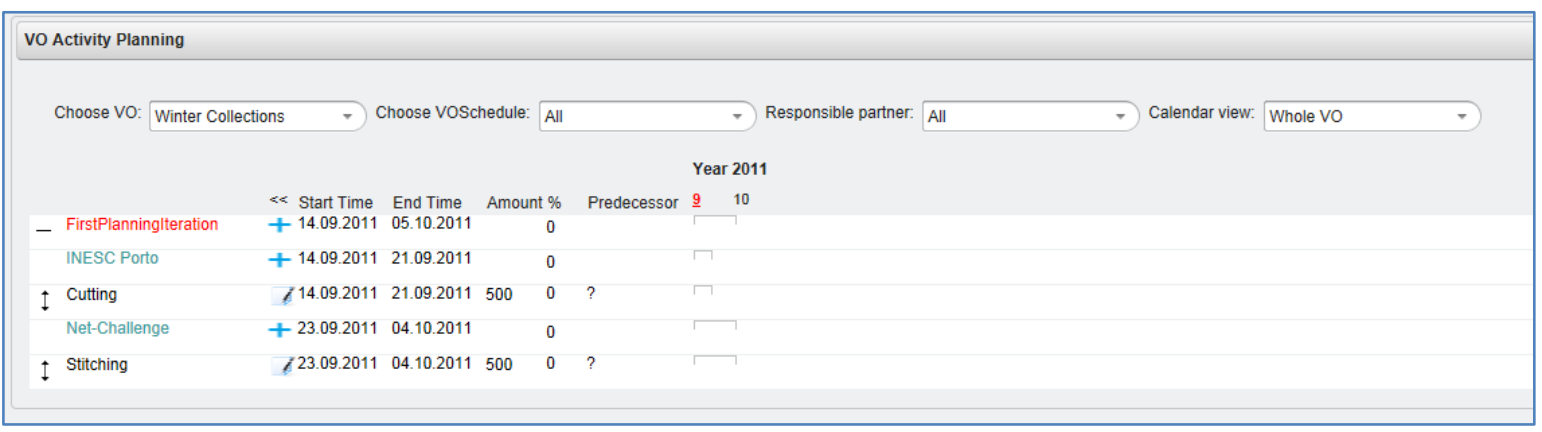

Figure 5. Collaborative planning sample screen.

For company A, a web-based tool like the one presented assumes a crucial role in the organisation, especially because their business model is based on the subcontracting of all manufacturing operations. This makes it possible for company A to define an initial plan (which responds to customer delivery dates) and asks partners to validate and suggest any changes. The negotiation process starts with partners planning their allocations according to their local production capacities on a shared web-based platform, instead of exchanging e-mails or phone calls. Any change performed allows partners to evaluate the impact of their suggestion and allows company A to visualise and efficiently manage the overall planning. It also significantly reduces the amount of unstructured data and communication errors between all of the companies involved, making it possible to focus on value-adding activities and enabling better management.

Once the plan has been agreed by all partners, it can be used to present the quotation to the customer. When the customer confirms, the order operation starts and the Monitoring and Event Management component is used to track the planned operations and unforeseen events are managed when they occur. If critical deviations are identified, collaborative planning is used to agree on a new plan. 


\subsubsection{Evaluation of the Net-Challenge Framework in the business case}

The proposed Net-Challenge framework introduces the advantages of creating a truthful collaborative environment, including accurate business process management and integration concepts. The major business processes which were considered were:

- Collaborative design

- Search for partners

- Selection of partners (based on a multi-criteria serialisation)

- Collaborative planning (aggregate and detailed)

- Operations monitoring

- Performance management.

The proposed approach is based on the active participation of all partners in the critical processes of these two companies. Processes such as operations planning are becoming collaborative and the intuitive sharing of ideas and information along with structuring information for later use will reduce the risk of losing or repeating information. Collaborative planning was a huge challenge, enhancing the planning negotiation and ensuring a sustainable decision. It will allow companies to match their commitments with the VO and with their local production planning.

This approach allows textile companies to reach their customers and suppliers in a different way. The relation would derive from "customer-to-supplier" to "win-to-win", sharing ideas and risks and enhancing trust between partners. A major advantage would be the ability to share knowledge and competencies, ensuring a quicker and more professional response to customers. Companies like company A or B need to contact partners individually (which means several phone calls and e-mails/ exchanging technical documents) like those presented in the current scenario. Thanks to the support of the Net-Challenge framework, communication and information shared by all partners is more streamlined, ensuring transparency and creating a truthful collaboration environment, as presented in the proposed scenario.

The application of this strategy can drastically reduce all manual tasks and also enhance a partner's participation in and the validation of several business processes, reducing potential errors and increasing the efficiency of process. The proposed approach also ensures that companies can respond to unpredicted events, triggering warning actions to partners and supporting the definition and implementation of corrective solutions. Another key advantage is the overall planning and control of the virtual organisation which would become much easier and more visible to all partners.

\subsection{Collaborative Business case 2}

\subsubsection{Company backgrounds}

The footwear sector represents one of the traditional pillars for products "Made in Europe". It is also one of the most important sectors for European manufacturing. As in other mature sectors, footwear is currently witnessing a crucial period with the complex economic environment where market needs are increasingly characterised by requests for product customisation and short lead times.

The network under consideration is composed of a shoe producer and a fabric supplier that also collaborates with other partners and suppliers in the north of Italy in the Vigevano footwear district. In addition to being a shoe producer, Company $\mathrm{C}$ also helps stylists and shoemakers manage the complete supply chain for the design and production of small batches. The conception of new collections is achieved supporting fashion stylists in the industrialisation of new ideas, through CAD services, training and the exploitation of digital technologies. The promotion and distribution of products is handled involving independent commercial organisations, whose selection is based on their market orientation and their familiarity with the products. Company $\mathrm{C}$ can also act as a consulting and service company, offering qualified support for production re-engineering, the modification of operating machines or the conception of new mechanical technical solutions.

In a few years, Company D became a leading company in the market for high-fashion fabrics for shoes, accessories and clothing. The company is deeply rooted in the industrial culture of the district where it is located and has developed outstanding innovative and technological strength in the design of fashion fabrics and hi-tech materials, making it a reference point for "Made in Italy" products as well as for renowned international industries. Today, the share of revenues from the footwear sector is approximately $40 \%$ of the total in comparison to the accessories and apparel market. Research, innovation, quality and service are the reasons behind company D's success, ensuring customer satisfaction based on three different product families: a basic line that includes their best selling basic products, a fashion line, where the company expresses its finest 
creativity with seasonal collections and special products; and a technical line, which includes products with the highest technological and functional content due to the material components or the sophisticated treatments.

Company D is a frequent partner of company $\mathrm{C}$, both in a customer and supplier role which means that sometimes shoe producer $\mathrm{C}$ is the customer, requesting the provision of a specific fabric for shoes, and sometimes shoe producer $\mathrm{C}$ is the supplier, providing shoe samples to test innovative materials.

\subsubsection{Objectives and collaboration needs}

Nowadays in addition to aesthetic needs, footwear ranges are being driven by specific customer features (special sizes, behaviour, age, health conditions). For this reason, footwear is one of the industries that is being affected and will be more affected and transformed by the Mass Customisation paradigm.

In footwear networks, component and material suppliers, such as last, heel and sole makers, are important key business partners, namely "core partners". These "core partners" often have a strong influence on product definition because they are involved from the beginning of a shoe/collection project and in the whole conception and design process. Their proactive contribution is especially unavoidable when design and production follows (or drives) fashion and/or technological trends. The collaboration is currently based on direct relationships and partner selection. At the moment the integration of customised orders with mass production orders is managed based on urgency.

The application of the Net-Challenge methodology is based on the fact that the VO formation starts with the analysis of market needs and the definition of contractual and nondisclosure conditions in order to define the High Level Product Platform, which represents a new Shoe Collection. At this stage, the VO is mainly formed of company $\mathrm{C}$ and the stylist who analyses the requirements and selects the right partners for the collaborative definition of the product platform and all of its components. Following this step, an estimation of costs and benefits and a negotiation of the distribution of benefits between partners can take place. If the project is accepted by the VO members, the VO contract is then formalised.

Following the agreement, the VO partners design and engineer all of the product models included in the Shoe Collection, preparing the Product Platform. Company D has a crucial role in the definition of the features of the shoe collection since it is actively involved by company $\mathrm{C}$ and the stylist at the early stage of high level product concept. The complexity of product development in the footwear companies is in the detailed engineering of product platforms (shoe collection) due to the need to develop each product model in different variants and sizes. This implies the need for engineering planning based on the coordination of the shoe producer with other partners in the VO, each being involved in order to engineer their own components. The Net-Challenge methodology can support the definition of the Product Platform and all of the possible product combinations to enable customisation and make it possible to produce detailed lists of components and price tables.

The partner search which is performed in the "VO Form" phase is strategic because the component producers involved in $\mathrm{VO}$ during the design phase should be the same as those participating in the production phase. This will avoid not only wasting time searching for new partners, but also wasting time explaining the product concept to them. When a customer asks for a specific customised shoe from the proposed collection, the product has to be configured and adapted according to his/her requirements and according to the relative degree of customisation. This step does not include the simple assembling of components, as typically performed in the ATO scenario, it includes a real reconfiguration where specific components, such as the shoe last, soles or heels, may need to be redesigned. It may also be necessary to search for new partners with competencies that are not present in the VO.

\subsubsection{Implementation of the methodology and the web platform}

The ability to cooperate in the shoemaking industry is strongly based on the availability of common working environments, where fundamental values and goals could be shared and understood by each stakeholder. The implementation described in this document adopts the Net-Challenge $\mathrm{BC}$ as a robust backbone to build such an environment. It constitutes the solid foundations for a reciprocal trust relationship between partners and for the definition of common objectives.

Once links exist between companies, the frequent exchange of ideas and information is both a fundamental requirement and an ultimate aim of their collaboration; this is true not only for human interaction but especially for communication between information systems. The Net-Challenge platform offers several tools to support such information exchange in the form of repositories for shared documents, access rules and control, common vocabulary of terms and ontologies based on semantic web technologies, online tools for product engineering, process planning and risk management.

The Net-Challenge $\mathrm{BC}$ has been adopted as an ideal closed world where it is possible to safely apply some of the interoperability technologies aimed to broaden scope, namely the web and the semantic web, where control 
could be lots over implications and complexity. This is the environment area in which the common terminology and concepts are defined in order to build the foundations for any subsequent cooperation. Such a principle has been applied in different contexts, from defining contracts to planning rules, to product engineering, to risk and event management.

Based on such an agreement, experimental VOs are being defined to address specific business opportunities, with lifecycles that are defined and controlled by the Net-Challenge methodology and by the supporting tools. Information could be shared during each phase by means of several targeted tools, which support both the paradigmatic dimensions of the business, namely the product definition and its possible derivations, and its syntagmatic dimension, represented by cooperative planning and event management.

In the shoemaking application case, in particular, the possibility of creating common ontologies and adopting existent ones from the semantic web community has been exploited and experimented in depth, especially in the areas of product concept and engineering. The basic idea of a multilevel BOM has been explored, exploiting the freedom to add controlled information at any level of the product definition, from the shoe as a whole to the internal composition of each component and material. This possibility offers the opportunity to design products with more control over the inner nature of their internal structure and composition, incorporating the contribution of each of the partners involved. To support such a process, a specific extension has been developed on the website of both companies $\mathrm{C}$ and $\mathrm{D}$ to expose ERP data in the same format as the NetChallenge platform, thus fully integrating the partner's ICT environment and the BC.

The following picture illustrates an example of web-based navigation in a multilevel BOM, where each product (shoes in this case) is documented in terms of its constituent parts and production steps. Arbitrary properties based on predefined ontologies may be added to each level of the BOM hierarchy. A 'remote' view of the same information is accessed online from the ERP of the corresponding manufacturer, provided that it exposes the pertinent information following the compliant format and protocol.

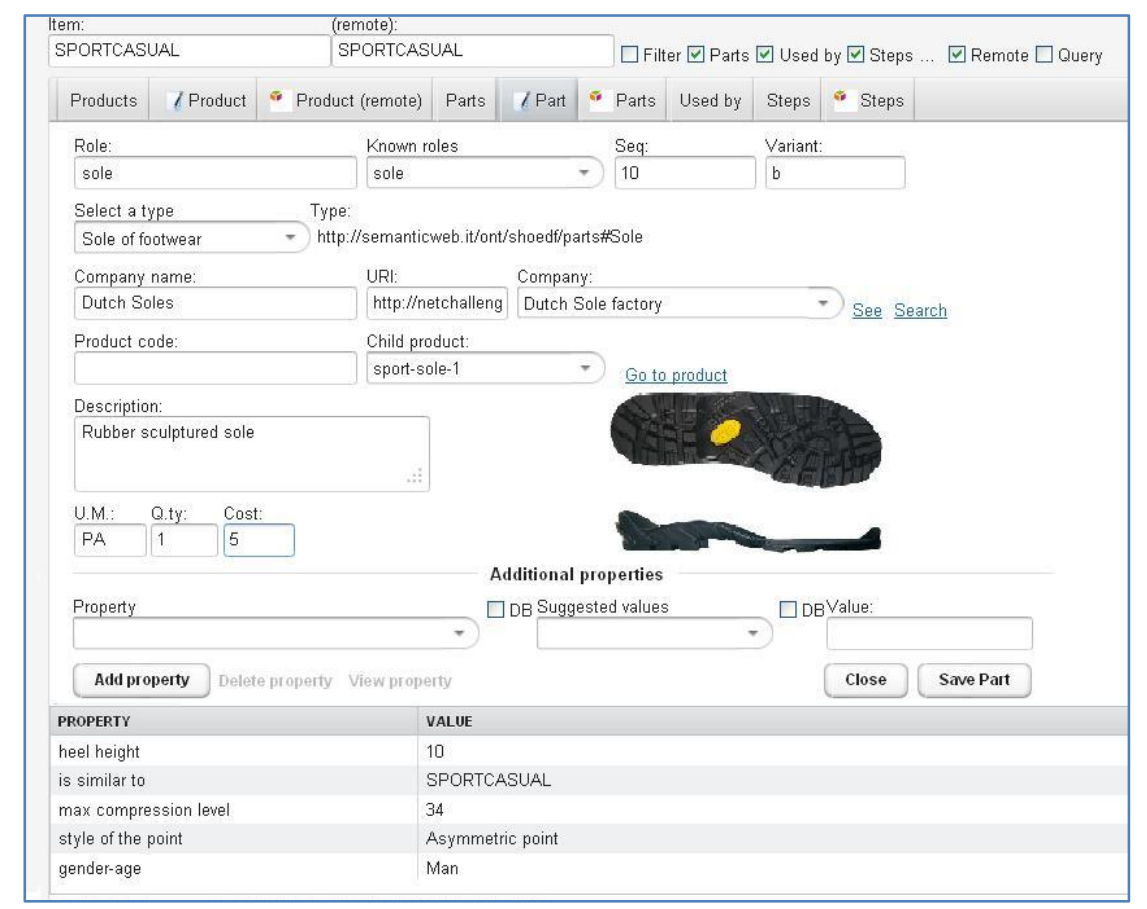

Figure 7. Product design sample screen.

The shoemaking life-cycle has the prerogative of involving several SMEs from the very first phases of product design, with each of them being very important in the definition of the final product. For this reason, planning the activities is usually a challenge because it requires the agreement of several independent partners. The application of the Net-Challenge methodology for collaborative planning, supported by the specialised tools offered by its platform supports the management of such a critical phase involving all of the stakeholders allowing them to make their contribution and controlling their commitment to guarantee the final schedule is followed. An online GANTT application allows the partners to control the progress of the activities at a VO level. The application also issues programmed warnings when accidental (but foreseen) events arise. This helps keep the business on schedule and guarantee the desired overall performance of the VO. 


\subsubsection{Evaluation of the Net-Challenge Framework in the business case}

The Net-challenge methodology and ICT platform's contribution to footwear practices is based on the improvement of the relationships in the footwear chain through the development and introduction of easy to use methods and tools to support the exchange of knowledge especially during product conception and the creation of VOs. Advanced methods support the creation of BOM where product costs and partner assignment to components complete standard product data, providing an open platform to share product data and for stakeholders to communicate with remote access to information.

Considering every product may require the collaboration of different partners, based on their specific competences, the creation of VOs gives companies in the footwear sector the flexibility to meet customer requirements. A key selection factor is a partners availability in order to be able to promptly respond to small orders with exceptions in accordance with the customisation process.

The major business processes which were considered crucial and applicable by the Net-Challenge Framework were:

- Collaborative design based on a list of shared components among partners

- Partner Search

- Partner Selection (based on a multi-criteria approach)

- Collaborative planning (aggregate and detailed)

- Performance management.

The Net-Challenge application was based on the active participation of some important partners in the two companies' critical processes. Processes such as Product Design are expected to be collaborative, this means sharing ideas and information in an intuitive approach and structuring data for later use. This will reduce problems relating to loosing or repeating information.

The application of the Net-challenge approach allowed footwear companies to reach their suppliers not through a vertical relationship but sharing ideas and risks and enhancing trust. A major advantage would be the ability to share knowledge and competencies, ensuring a quicker and more professional creation of a collection than with standard procedures. For companies like company C and D, they needed to contact partners individually (which means several phone calls and e-mails/ exchanging technical documents). The application of the strategy proposed by Net-Challenge tools was evaluated by the companies as a valid support that reduced manual tasks and validated several business processes, reducing potential errors and making processes more efficient. Another key advantage that companies C and D considered relevant was the possibility of applying VO planning and control, making the process easier and more visible for all partners.

\section{Discussion and conclusions}

This paper presents the Net-Challenge framework and how it has been applied to fashion networks. The innovation proposed by the Net-Challenge framework is based on the definition of an operative guideline and an ICT platform for NHN implementation by SMEs. These tools make a further advancement in theoretical research on VBEs and VOs because they support collaborative ETO and CTO scenarios for NHNs in particular and specifically for complex or customised products. For these environments innovative concepts and tools were designed for collaborative design, collaborative planning and event management. The approach developed by the research team has been applied to the case companies both as a strategic consultancy tool and as an operational ICT tool. The applicability to the theoretical approach has been guaranteed by the fact that the Net-Challenge framework has been developed collecting continuous feedback from case companies with an iterative approach.

In the Net-Challenge methodology the creation of BCs is based on a long-term based strategy as an evolution of VBE: in BCs, groups of SMEs share a common web space as a means of advertising and sharing activities based on trust, collaboration and the development of social relations. BCs in the Net-Challenge platform are created by SMEs mainly to be able to respond to market challenges which cannot be met by single SMEs. BCs can be created as an evolution of industrial clusters with a specific strategy which brings together certain companies. The proposed low cost and easy to implement technological solutions make it possible to quickly become part of a $\mathrm{BC}$ and create VOs within this context.

As a result of the implementation in the business cases, it can be seen that the development of regional or sectorial BCs, where trust can be built and communication can be streamlined between a large number of SMEs, will increase the potential to respond to market opportunities quickly and efficiently. In order to cope with the turbulent business environment and meet customer demands efficiently and effectively SMEs cannot remain isolated. The results of this research and its application for business cases highlight the importance of promoting dynamic BCs to enable a fast and efficient response to market opportunities. The Net-Challenge methodology 
and platform have been tested as a valuable support for SMEs to guide the network formation and partner qualification by sharing information. This approach is based on partners sharing necessary data in order to establish collaborative networks, supporting the partner search as well as their qualifications and the creation of VOs. Operational ICT tools to support collaborative design, collaborative planning, monitoring and event management bring decisive improvements in terms of reduction of the delivery time, costs and innovation potential. The increased visibility on all partners' activities allows significant improvement in process management, decision making and conflict resolution.

Critical success factors derived from the implementation of the Net-Challenge methodology and related ICT platform are linked to the fact that SMEs can exchange documents and control ongoing processes adopting methodologies to share knowledge with trustworthy partners. The networking partners need social business solutions that are easy to use but still include the confidentiality aspects needed for business transactions making it possible to formalise dedicated non-disclosure agreements according to the specific needs of each component.

Critical success factors for NHNs are measured by comparing the value of several predefined variables, such as the quality of communication and participation, conflict resolution techniques, coordination and trust and partnership attributes of commitment (Mohr et al., 1994). According to the results of the research and the application of the theoretical approach to real cases, the key success factors for the implementation of the NetChallenge framework can be summarised as follows:

- The development of trust between participants in BCs;

- The development of change management programs to reduce opposition to changes of personnel at different levels of each organisation and of the network;

- Clear, aligned and shared objectives between participating companies;

- New well-defined, clear and formalised roles for all partner companies;

- Formalised and standard collaboration process;

- The willingness to share knowledge, competencies and experiences with partner companies;

- Human resources with the necessary technical skills and collaboration experience;

- Shared values between the companies in the business community;

- A critical mass of financial resources for the defined strategic objectives.

Further research activities will focus on the Net-Challenge platform in order to implement all of the most important steps of the methodology in the ICT platform. New supporting tools will be used to configure the companies to increase their networking capability. Further business cases will be analysed in order to evaluate the applicability of the platform both in the fashion sector and in other sectors where the relevance of SMEs is large and the need for NHN implementation is rapidly growing.

\section{Acknowledgements}

The authors would like to acknowledge that the European Commission co-funded this research as part of the NMP priority of the Seventh RTD Framework Programme (2007-13) for the Net-Challenge project (Innovative Networks of SMEs for Complex Products Manufacturing), Ref. CP-FP 229287-2. The authors also acknowledge the valuable comments from reviewers and the collaboration from the project team during this research.

\section{References}

Afsarmanesh, H. and Camarinha-Matos, L.M., 2005. A framework for management of virtual organization breeding environments. In: L.M. Camarinha-Matos, H. Afsarmanesh and A. Ortiz (Eds.). Collaborative networks and their breeding environments, International Federation for Information Processing (IFIP), 35-48, New York; Springer.

Afsarmanesh, H. and Camarinha-Matos, L.M., 2008. The ARCON modeling framework. In: Collaborative networks: Reference modeling (eds), Springer Place New York, NY, 67-82.

Appel, W. and Behr, R., 1998. Towards the theory of virtual organizations: a description of their formation and figure. Virtual-Organization. Net Newsletter, 2(2), 15-36. June.

Ahuja, M.K. and Carley, K.M., 1998. Network structure in virtual organizations, Journal of Computer-Mediated Communication, 3( 4), Available on: http://jcmc.indiana.edu/vol3/issue4/ahuja.html

Almeida, R., Toscano, C., Azevedo, A., Carneiro, L, 2011. Collaborative planning approach for non-hierarchical networks environments, Proceedings of the ICE 2011 conference.

Camarinha-Matos, L.M. and Afsarmanesh, H., 2004. Collaborative networked organizations - a research agenda for emerging business models. Kluwer Academic Publishers, ISBN 1-4020-7823-4, March.

Camarinha-Matos, L.M., Afsarmanesh, H. and Ollus, M.,2005. Virtual organizations - systems and practices, Springer.

Camarinha-Matos, L.M. and Afsarmanesh, H., 2005. Brief historical perspective for virtual organizations. In: Virtual Organizations - Systems and Practices, Springer.

Camarinha-Matos, L.M. and Afsarmanesh, H., 2007. A comprehensive modeling framework for collaborative networked organizations. Journal of Intelligent Manufacturing, 18, 529--542.

Camarinha-Matos, L.M., Afsarmanesh, H. and Ollus, M., 2008. Ecolead and CNO base concepts. In: Methods and Tools for Collaborative Networked Organizations (eds), Springer Science+Business Media, LLC. 
Carneiro, L.M., Almeida, R., Azevedo, A.L., Kankaanpaa, T, Shamsuzzoha, 2010. An innovative framework supporting SME networks for complex product manufacturing, Proceedings of PRO-VE'10 - 11th IFIP Working Conference on VIRTUAL ENTERPRISES, October 2010, Saint-Etienne, France.

Chituc, C.-M. and Azevedo, A., 2006. Business networking - the technological infrastructure support. In: M. Cunha and G. Putnik, Editors. Knowledge and Technology Management in Virtual Organizations, 334-354, Chapter 16, Idea Group Publishing, ISBN 978-1599041650.

Chituc, C.-M., Azevedo, A. and Toscano, C., 2009. A framework proposal for seamless interoperability in a collaborative networked environment. Computers in Industry, 60 (5), 317-338.

Cunha, P.F., Ferreira, P.S., Rintala, S., Shamsuzzoha, A. and Carneiro, L., 2011. A framework for event management within networks of SMEs for complex products. In Proceedings of the $17^{\text {th }}$ International Conference on Concurrent Enterprising, June 20-22, Aachen, Germany.

Davidow, W. and Malone, T., 1992. The virtual corporation. Harper Business.

Doumeingts, G., Chen, D., Vallespir, B., Fenie, P. and Marcotte, F., 1993. GIM (GRAI Integrated Methodology) and its Evolutions - a methodology to design and specify advanced manufacturing systems. In Proceedings of the JSPE/IFIP TC5/WG5.3 Workshop on the Design of Information Infrastructure Systems for Manufacturing, IFIP Transactions; B-14, 101-120, North-Holland.

Hobday, M., 1998. Product complexity, innovation and industrial organisation. Research Policy, 26, 689-710.

IFIP-IFAC TFAEI, GERAM, 2003. The generalized enterprise reference architecture and methodology, IFIP-IFAC Task Force on Architectures for Enterprise Integration. In: P. Bernus, L. Nemes, G. Schmidt, Eds. Handbook on Enterprise Architecture, 22-63, Springer, Heidelberg.

Kankaanpää, T., Shamsuzzoha, A., Carneiro, L., Almeida, R., Helo, P., Fornasiero, R., Ferreira, P.S. and Chiodi, A., 2010. Methodology for Non-Hierarchical Collaboration Networks for Complex Products Manufacturing. Proceedings of 16th International Conference on Concurrent Enterprising, June 21-23, 2010, Lugano, Switzerland.

Katzy, B., Zhang, C. and Loeh, H., 2005. Reference models for virtual organizations. In: L.M. Camarinha-Matos, H. Afsarmanesh, M. Ollus (Editors). Virtual Organizations: Systems and Practices, , Springer.

Myers, J., 2006. Future Value Systems: Next Generation Economic Growth Engines \& Manufacturing. In: Proceedings of the IMS Vision Forum 2006, 30--47, Seoul, Korea .

Nagel, R. and Dove, D., 1995. $21^{\text {st }}$ century manufacturing enterprise strategy. Bethelhem: Iaccoca Institute, Lehigh University.

Paszkiewicz, Z. and Picard, W., 2009. Modeling virtual organization architecture with the virtual organization breeding methodology. In: Leveraging Knowledge for Innovation in Collaborative Networks, Springer Boston, 307, 187-196.

Romero, D., Galeano, N. and Molina, A., 2008. A virtual breeding environment reference model and its instantiation methodology. In: Camarinha-Matos, L.H. eds. Pervasive Collaborative Networks (eds), Willy Picard, Boston: Springer, $15-24$.

Romero, D. and Molina, A., 2009. VO breeding environments \& virtual organizations integral business process management framework. Information System Frontiers (ISF), 11, 569-597.

Romero, D., Galeano, N. and Molina, A., 2010. Virtual organization breeding environments value system and its elements. Journal of Intelligent Manufacturing, 21, 267-286.

Shamsuzzoha, A., Kankaanpää, T., Almeida, R., Carneiro, L., Wiersema, J., Ferreira, P.S., Loichate, M., Hormazabal, N., Fornasiero, R., Chiodi, A. and Rintala, S., 2011. Net-Challenge Methodology, Final version, Delivery D1.6, NetChallenge project.

Tolle, M., Bernus, P. and Vesterager, J., 2002. Reference models for virtual enterprises. In: L.M. Camarinha-Matos. Editor. Collaborative business ecosystems and virtual enterprises, , Kluwer Academic Publishers.

Vernadat, F. and Kosanke, K., 1992. CIM-OSA: a reference architecture for CIM. In: Proceedings of the IFIP TC5/WG5.3 Eight International PROLAMAT Conference on Human Aspects in Computer Integrated Manufacturing, IFIP Transactions, B.3, 41-48, North-Holland.

Zachman, J.A., 1987. A framework for information systems architecture. IBM Systems Journal, 26(3). G321- 5298.

Zwegers, A., Tolle, M. and Vesterager, J., 2003. VERAM - virtual enterprise reference architecture and methodology. In: Proceedings of GLOBEMEN - Global Engineering and Manufacturing in Enterprise Networks, VTT Symposium 224. 